\title{
Optimization Strategies of Intersection Based on Non-motor Vehicle Priority in Old City
}

\author{
Lin DU \\ BEIJING UNIVERSITY OF \\ CIVIL ENGINEERING AND ARCHITECTURE \\ Beijing 100044, China \\ 18810454546@139.com
}

\author{
Pengpeng JIAO*, Honglin WANG \\ BEIJING UNIVERSITY OF \\ CIVIL ENGINEERING AND ARCHITECTURE \\ Beijing 100044, China \\ jiaopengpeng@bucea.edu.cn
}

\begin{abstract}
The development of traffic in old city, with the background of green traffic, is paying more attention to environmental protection. The public bicycle system is very appropriate for the development of old cities, and the order and efficiency of non-motor vehicles at the intersection are the key issues for the transportation system. Based on the traffic problems at the intersection, the disturbances among non-motor vehicles are analyzed, as well as the management measures. Some strategies are then put forward to optimize the channelization and traffic signal control of both big and small intersections in old city. Conclusions show that the strategies are rather effective in the optimization of intersections in old city.

Index Terms - environmental protection, at-grade intersection, public bicycle system, optimization strategy.
\end{abstract}

\section{INTRODUCTION}

With the development of economics, the number of Nonvehicle continuous downward trend, which still plays an irreplaceable role in urban transport system. Currently, the proportion of bicycle trips in Beijing is $18.1 \%$, especially in the area of Dongcheng District and Xicheng District of Beijing City as the representative of the ancient city, in order to improve the transportation and tourism environment, Public Bike System is vigorously developing. Due to the restrictions of heritage conservation, there are a lot of narrow roads in old city. Dongcheng District, Beijing, for example, in trunk roads, secondary roads and slip roads is the proportion of 1:1.6:2.3, also includes a large number of alleys. old city formed great amount of small and irregular junctions, which different from ordinary urban intersections, these intersections should be given adequate attention.

This paper mainly for the signalized intersections in the old city district of slow traffic system, put forward optimization strategy and provide some references to non-motor vehicle optimization at intersections.

\section{INTERFERENCE ANALYSIS OF NON-MOTER VECHICLES}

Table1 is the non-motor vehicle survey data about intersection in the vicinity of Lama Temple in Beijing.

Table 1, shows that the proportion of non-motor vehicles turn left is generally high, then it makes an increase in the number of conflicts and affects the motor vehicle and nonmotorized traffic efficiency.

TABLE I. HOUR TRAFFIC OF NON-MOTOR VEHICLES

\begin{tabular}{|c|c|c|c|c|c|c|}
\hline & direction & $\begin{array}{c}\text { turn } \\
\text { left }\end{array}$ & $\begin{array}{c}\text { go } \\
\text { straight }\end{array}$ & $\begin{array}{c}\text { turn } \\
\text { right }\end{array}$ & gross & $\begin{array}{c}\text { turn left } \\
\text { ratio/\% }\end{array}$ \\
\hline \multirow{3}{*}{ intersection } & east & 239 & 264 & 15 & 515 & $46.40 \%$ \\
\cline { 2 - 7 } & south & 460 & 427 & 19 & 921 & $49.90 \%$ \\
\cline { 2 - 7 } & west & 200 & 317 & 48 & 556 & $35.40 \%$ \\
\cline { 2 - 7 } & north & 346 & 561 & 41 & 948 & $36.50 \%$ \\
\hline
\end{tabular}

Through the investigation of the key road sections and intersections in unhistorical district in Dongcheng District found some problems, for example, non-motor vehicle facilities that on the sections is sound basically, load factor is generally small, but to intersections, formation of mixed traffic flow due to the limitations of time and space, the intersection running order confusion, it can easily result in the intersection running sluggish.

According to the particularity of intersection in the old city, through the analysis of operation situation of non-motor vehicles at the intersection, interference of non-motor vehicles mainly from the following:

(1)In the old city of the district intersection area, the nonmotor vehicle turn left is still a difficult problem. Features in the intersection region of non-motor vehicle is gathered through, from traffic flow, non-motor vehicle left turn radius is larger than the motor vehicle and speed is below, therefore cause serious safety problems in motor vehicle and non-motor vehicle collision point.

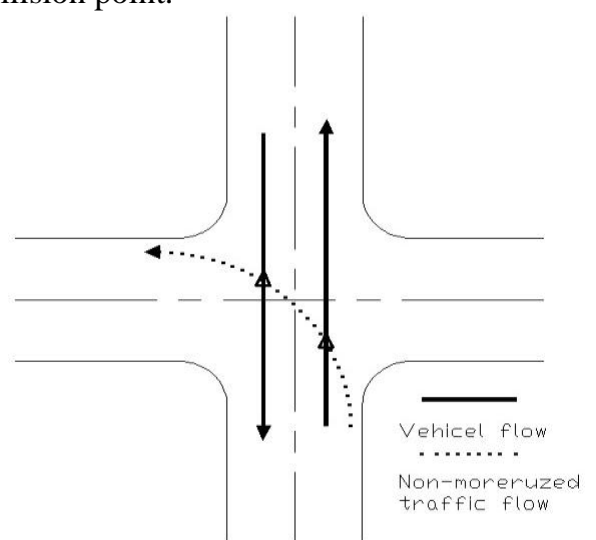

Fig.1: Conflict with straight motor vehicle schematic diagram 


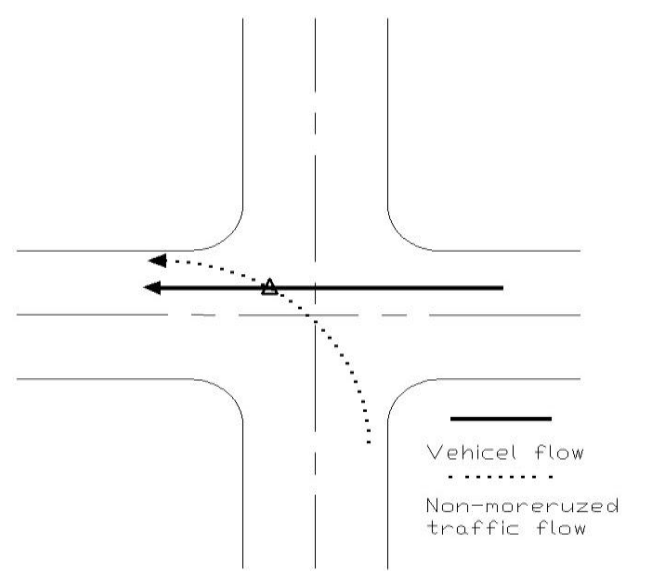

Fig.2: Conflict with vertical motor schematic diagram

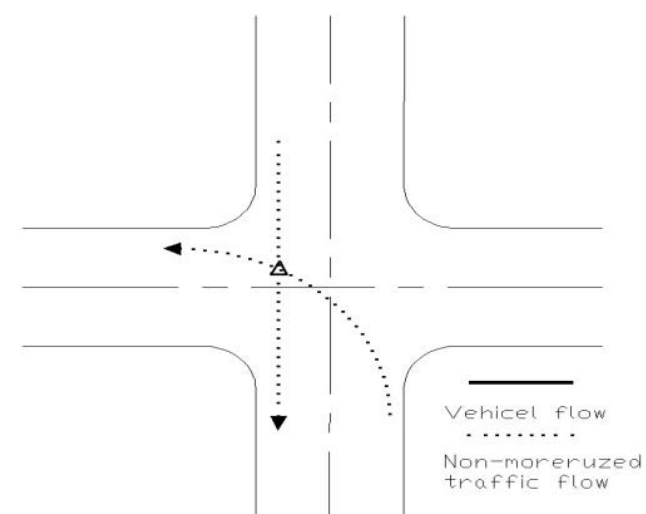

Fig.3: Conflict with opposite direction non-motor vehicle schematic diagram

(2)In the old city, because of the limitation of the roadway width, it produced a large number of small intersections and signal control systems in these district use two phases. Under the traditional two phase signal control system, the full red time of the intersection is designed by the time of motor vehicle clears the intersection, and because of the last phase tends to the non-motor vehicles those are not out of the intersection, which leads to the next phase delays the motor vehicle starting., then the lateral non-motor vehicles don't clear the intersection as usually, which dues to delay the motor

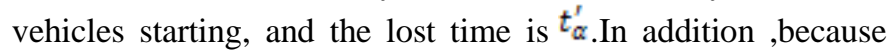
non-motor vehicles starting is faster than a motor vehicle and the non-motor vehicles that turn left conflicts with straight motor vehicle, which adds the straight motor vehicle starting lost time, the time is $t_{\alpha}^{a s}$. ${ }^{[1]}$

At the signal controlled two phases intersections which are confused by the non-motor vehicles, the time of the motor vehicle phase $\mathrm{e}^{[2]}$ is:

$$
\mathrm{T}=t_{\alpha}+t_{\alpha}^{s}+t_{\alpha}^{n}+f_{t}+t_{0}+t_{b}
$$

where, $t_{\alpha}$ - the time of the motor vehicle starts; $f_{t}$ - the correction coefficient of that the non-motor vehicle lateral block increases the saturation headway; $t_{0}$ - the lost time which is caused by that the non-motor vehicle across the gap of the motor vehicles delays the motor vehicles travel; ${ }^{t_{b}}$ - the unused time that is caused by the signal light transforms.
Based the above, the confusion between non-motor vehicles and motor vehicles increases the time of the motor vehicle phase and reduces the traffic efficiency of intersection.

All in all, the confusion between non-motor vehicles and motor vehicles at the intersections is mutual, which is centered on the conflict points in the functional area ${ }^{[3]}$. So, solving the conflict is the key to intersection optimization design, and related optimization measures and strategy must be built around this.

\section{THE TRAFFIC MANAGEMENT APPROACH OF NON-MOTOR VEHICLE AT INTERSECTIONS}

Based on the basic characteristic of the non-motor vehicle and the traffic management principle of the non-motor vehicle, this paper summarises the traffic management measures of the non-motor vehicle used at the intersection.

\section{A. Facilities management}

\section{1)The turning lanes}

Right turn lane is that the existing roads are used to set up the special lane for bikes to turn right. The advantage of it is that can ease the traffic congestion in the intersection and is helpful for traffic safety. But this demands the wider intersection and the cyclist strictly abide the principle of the road.

The left turn lane is often used to deal with bicycle for turn left in the intersection in foreign counties, for example, the coloured pavement is said bike lanes for left turn in Japan, which limits the left turn bikes and reduces the interference to the straight motor vehicles from the left turn bikes. But this increases the bicycle distance and the cyclists are not used to this. So this measure applies only to that the traffic of turn left bicycles is little on its own, and this does not need to strengthen the traffic management of bicycle.

\section{2)The waiting zone for left turn}

The front of the bicycle import way in the intersection, the waiting zone for left turn is set up. The left turn bicycles run down to the waiting zone at the other side with the straight bicycles and move forward when the other direction green light lights. In the other word, this measure transfers that the bicycles turn left to that they go straight twice to achieve turning left.

It can eliminate the interference to the straight motor vehicles from the left turn bikes, so this measure can improve the running speed of vehicles through the intersection and the traffic capacity, besides that, this measure also can reduce the confliction point between the left turn non-motor vehicles and the straight motor vehicles, which is helpful for traffic safety.

the waiting zone for left turn. The defects of setting the waiting zone for left turn are similar to setting the turning lanes.

\section{3)The method of stop line moved up}

Draw the bicycle stopping line in front of the motor vehicle stopping line. When the green light lights, the bicycles go into the intersection first, this can avoid the congestion among the motor vehicles. So, this measure can increase the traffic capacity of the intersection and is helpful to the traffic safety. But only strengthen the education and management to the 
cyclist, through this, the cyclist will park the bicycle reasonably, this method can play a role as shown in the figure below:

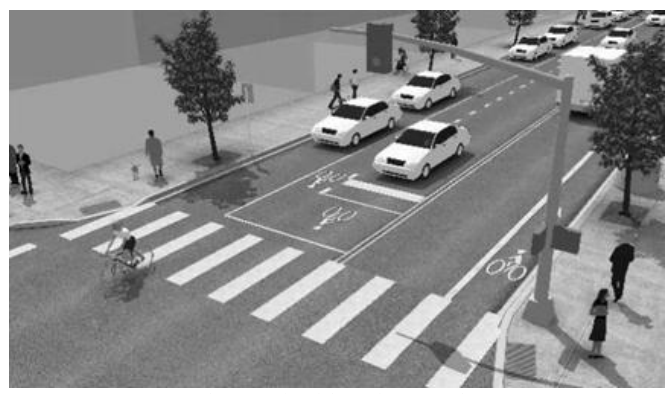

Fig.4: The bicycle crossing

4) The bicycle crossing

Draw the bicycle crossing on the arterial road. This can warn the driver to the horizontal bikes as the zebra crossing and the bicycle has the priority on the bicycle crossing. The motor vehicle should slow down before the bicycle crossing and should temporarily stop, let bicycles through first when crossing with a bicycle. Bicycle crossing is suitable for the branch (including alley, lanes, etc.) with the main road or secondary road plane intersections, also applies to some intersections that large building entrance cross with main road.

The four kinds of management measures of non-motor vehicles in the intersection discussed above are almost based the division of traffic lanes. This will lead to two results, on the one hand, because of the additional bicycle lanes, the bicycle running distance increases, this is not conducive to bicycle abiding the articles of association. On the other hand, from the view of the motor vehicle, add the bicycle turning lane to the already tension area of road use, this will inevitably reduce the traffic capacity of motor vehicles. So, the measures above must be carried out correspond to its background.

\section{B. Signal management}

The signal management method mainly is twice green lights. At the intersection imports, the stop lines of motor vehicle and bicycle are still in the same position. But in consideration of the characteristics of the bicycle which is starting faster and trooping through the intersection, we can turn the bicycle signal green light first, and let the bike group enter the intersection first, and then light motor vehicles a green signals light. The difference between the time of the first and the second green light is 5-15 seconds generally and the specific is determined by the size of the intersection's traffic flow and the geometry size of the intersection. The method of twice green lights can ease traffic congestion within the intersection, however, it extend the traffic signal cycle time. For the intersections in which the non-motor vehicle flow is very heavy while the motor vehicle flow is relatively small, the effect of adapting the twice green light is very obvious during the morning rush.

\section{OPTIMIZATION DESIGN OF NON-MOTOR VEHICLES AT INTERSTATIONS}

The design of non-motor vehicle at the intersection includes three vital elements: design of approach of non-motor vehicle ; design of left-turn lane of non-motor vehicle; design of signal control of non-motor vehicle. ${ }^{[4]}$ After investigating numerous intersections in old cities, it was found that, grades of road differ from each other due to the existence of preserved buildings and alley roads, multiple high-grade and low-grade intersections and small intersections are generated by road intersections. Optimization designs of various types of intersections are different. This paper presents optimization designs of large and small intersections respectively in allusion to characteristics of intersections in old cities.

\section{A. Optimization design of large intersections}

Large intersections mentioned in this paper mean the intersections between secondary and higher-grade main roads. The principle of optimization of large intersections in old cities is to emphasize the security of non-motor vehicle on the premise of motor vehicle's passing efficiency.

The concrete solution is to set left-turn vehicle-waiting for non-motor vehicles to ensure their security. ${ }^{[5]}$ The research related to traffic conflicts at intersections indicates that traffic conflicts not only correlate with volume positively, but also with severity of conflicts at the conflict point. The traffic equivalent conflict is regarded as the indicator of security at intersections, which can be described as following equation:

$$
c=k \sum_{i=1}^{n} \alpha_{i} Q_{i}
$$

Where $c$ represents the traffic equivalent conflict at intersections(time/h); $k$ represents correction factor, a constant; $\mathrm{n}$ represents the total number of conflict point at intersections; $\alpha_{i}$ represents the conflict converted coefficient at point i; $Q_{i}$ represents the total traffic volume at point $\mathrm{i}(\mathrm{pcu} / \mathrm{h})$.

From the equation above, it can be inferred that the security at intersections increases as the total traffic volume at conflict points decreases. Therefore, setting left-turn waiting-area and crossing for bicycle is a solution to reduce the conflict volume at conflict point of intersections, and then to guarantee the security of non-motor vehicle at the intersection. From survey data in Table 1, it is found that the average proportion of leftturn motor vehicles is $42.1 \%$. Set left-turn waiting-area for bicycle at large intersections in old cities, as shown in Figure 5, thus non-motor vehicles can cross the intersection taking advantage of stop clearance of motor vehicles, which may improve the vehicle order at intersections. By so doing, it relieve significantly the conflict between left-turn non-motor vehicle flow and straight motor vehicle flow from the same and opposite direction, as well as the conflict between left-turn non-motor vehicle flow and straight motor vehicle flow from vertical direction. The total traffic volume at conflict points is reduced. Thus the traffic equivalent conflict at intersections decreases, which enhances the security of non-motor vehicles. 


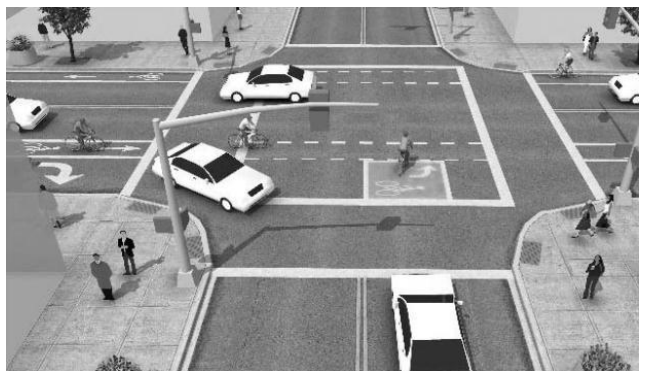

Fig.5: Non-motor vehicle left-turn waiting area

\section{B. Optimization design of small intersections}

Small intersections mentioned in this paper are referred to the intersections between secondary main roads, or secondary and lower-grade main roads. As to small intersections, the passing efficiency of motor vehicle should be put into minor position, leaving the priority to non-motor vehicle. The principle of optimization of small intersection in old cities is to ensure the priority of non-motor vehicle sufficiently, leaving the passing efficiency of motor vehicle behind into minor position. Combination of two green traffic lights and the set of lane lines for bicycles to control non-motor vehicles at intersections are presented.

In this paper, the management scheme of two green traffic lights and the set of crossing for bicycles are integrated to solve the problem of mixed flow at intersections. That is , dedicated signal light is employed taking advantage of characteristics of bicycles such as fast start-up, low speed and gregariousness. Lighten the green light for bicycle earlier than the green traffic signal in the same direction, when the bicycle group reach the conflict point between it and the motor vehicle flow permitted by previous green phase, the tail of motor vehicle queue should have all bear off the intersections. By this time, lighten the green traffic light for the motor vehicle in the same direction as the bicycle group. The time interval between the two green signal depends on different situations, $5-15 \mathrm{~s}$ generally. In fact, the time of lightening the green light for bicycles in advance can directly utilize the interval time of green traffic signal, which is to eliminate the necessary time of conflicts between vehicle flows. The speed of non-motor vehicle is far low then motor vehicle, hence the combination of this feature and determination of interval time of green traffic signal will not increase the signal period. Furthermore, it also shortens the waiting time for bicycle, and reduce the opportunities of bicycle's unlawfully crossing to improve the security and reduce traffic accidents.

Combined with specified crossing for bicycle, as shown in Figure 6, this scheme will yield better effect. The space of crossing for bicycles at intersections guarantee the right of passage for bicycle, which reflects the principle of priority for non-motor vehicle. With regard to the design of exact location for stop lines, rational design should synthesize the practical conflict points between motor and non-motor vehicle, thus to achieve the overall consideration of signal and stop lines, which will improve effectiveness of applying this solution. Besides, although some intersections have employ dedicated signal for non-motor vehicle, they are lightened at almost the same time as the ones for motor vehicle. Consequently, they do not proper function as expected.

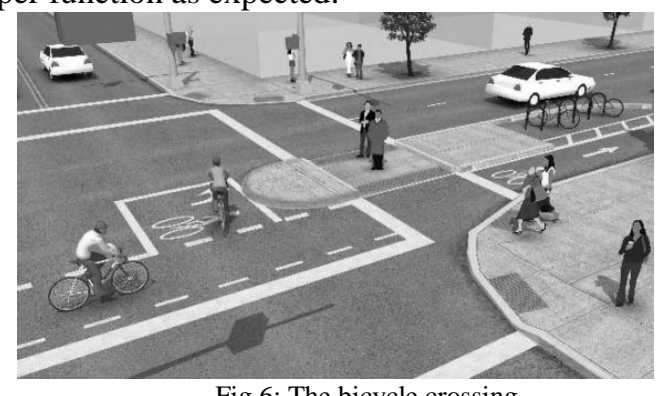

Fig.6: The bicycle crossing

\section{CONCULSIONS}

Non-motorized transportation, with the advantage of green, energy saving and environmental protective, meet the requirement of environment-friendly and resource-conserving. The management of non-motor vehicle at intersections in old cities is complex and crucial, which directly impact the passing efficiency and security of intersections.

In this paper, we present the set of left-turn vehicle-waiting area for bicycle at large intersections in old cities, which will ensure the passing security of non-motor vehicles at small intersections in old cities, we present the combination of stop line and traffic signal control, which will improve the conflict of motor and non-motor vehicle to guarantee the priority of non-motor vehicle sufficiently. In the subsequent study, we will analyze more types of intersections and propose corresponding optimum measures.

\section{ACKNOWLEDGMENT}

This paper is sponsored by National Natural Science Foundation of China (51208024) and Science and Technology Program of Beijing Municipal Commission of Education (KM201110016001). The authors are also thankful to anonymous referees for their hard work.

\section{REFERENCES}

[1] J. Y. Zhao, X. F. Yang, "Study on safety evaluation index of intersection of city roadway," Journal of Chang'an University, vol. 20, pp. 59-62.

[2] CJJ152-2010. Specifiation for design of intersections on urban roads[S]. China People's Republic of Housing and Urban-Rural Development,2010.

[3] Import and export management branch of the U.S. Transportation Research Board, The road entrances management manual[M].China Architecture and Building Press,2009

[4] G. Zhang, Z. B. Lu, X. F. Shi, "Research on crtical planning and design technology of non-motor traffic," Road Traffic and Safety, vol.10,pp.31-37.

[5] W. D. Glauz, D. J. Migletz, "Application of Traffic Conflict Analysis at Intersections," HS-028 882, Washington DC: National Cooperative Highway Research Program Record,1980.

[6] Y. H. Zhao, "Research on active signal control intersection traffic safety design of the basic theory and method". 